\title{
\#LIKEORUNLIKE: A descriptive study on the effects of social media on the moral development of the young people
}

Quimson, Leonardo O. Jr. $\varangle$

University of Santo Tomas, Philippines (loquimson@ust.edu.ph; leonardo_quimson@dlsu.edu.ph)

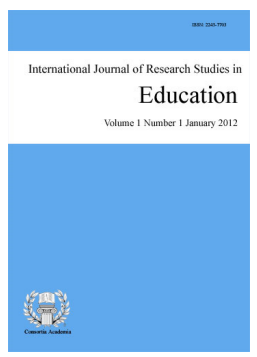

ISSN: 2243-7703 Online ISSN: 2243-7711

OPEN ACCESS

\section{Abstract}

Modern Technology has its purpose of making lives easier and helping people to connect. In the advent of fast pacing world through technology, the Internet and Social Media became a "need" in this present generation. It affects the way the people live at present, specifically the youth of today. In this current situation and reality, the researcher desires to have an in-depth study on this and try to look into what "social media" is as well as its purpose for us. This paper will also attempt to see the effects of social media on young people. The researcher will try to see the advantages or benefits of using this platform most especially in problem solving, creative and critical thinking skills, as well as easy access to communication to other people. On the other hand, this study will also try to discover the disadvantages or negative effects of social media to the young such as internet addiction, depression, cyberbullying, "sex texting", and peer pressure. Through a descriptive method and qualitative approach of research, responses will be gathered from the respondent young people or students through an interview. In relation to this, the study will also try to understand and connect the findings or results of the study to the theory on Moral Development by Lawrence Kohlberg, an American psychologist, and James Fowler, an American theologian and professor, in his stages on Faith Maturity and Development as well as some of the social teachings of the Catholic Church which speak about the importance of the role of the parents in the formation of the young people as moral responsibility. To end this study, the researcher will give some recommendations to fellow educators, parents and guardians on how to deal with this reality of "social media" and continue to become values formators of the young people at present.

Keywords: media; Facebook; Internet; moral development; youth 


\section{\#LIKEORUNLIKE: A descriptive study on the effects of social media on the moral development of the young people}

\section{Introduction}

Children nowadays are already called "digital natives". They were born in an era where they have headphones attached on their navels, communicating at home through "Messenger" even if they are roommates, having meetings, school group works and even dating online via Facebook, Skype and other web portals. They are having internet sensations that they look up to or "lodi's" (Filipino coined word for "idol") that they like and follow in Instagram and Twitter. They already lived in the "world and culture of instant". Through Google, a worldwide famous search engine, they can easily get answers to their question by just a click. With subscription to Spotify and Netflix, they can freely choose and listen on their favorite songs and watch many genres of movies just on their fingertips through computer or smartphones. With these digital realities happening, what should be the stand and response of the parents, guardians and teachers, who are called as "the digital migrants", because they were not born in this period where in Internet and Social Media seems to be a must? They were having a hard time in reaching out to them and wanted to be connected in their other "social environment" creating their own entertaining world aside from what we really have. With this, "many parents worry about how exposure to technology might affect toddlers developmentally... In fact, experts worry that the social media and text messages that have become so integral to teenage life are prompting anxiety and lowering self-esteem" (Emhke, 2017). Moreover, "such enormous increase of the youth using social media in the world, a lot of concerns cut across from parents, Church leaders, politicians and educationists on the unknown effect of social media in various aspects of human life. It is therefore very important to check on the influence of social media... particularly in the life of a student" (Alejandrino et al., 2018).

With this reality at present, the researcher decided to see on what social media is and what are the effects, positively and negatively, to the young individuals especially in their moral behavior and development. The research will try first to define what "social media" is and its purpose. Later on, the study will present some situations in other parts of the globe that will help us see how far "social media" is already reaching many people's lives and how it affects the morals and values of young people.

It is important to know first the meaning of "social media". Social Media or Social Networking Sites are termed to as web based services that give an opportunity to individuals to create their own personal profile with the choice of their own list of users and thereby connect with them in an altogether public forum that provides them with features such as chatting, blogging, video calling, mobile connectivity and video/photo sharing (Khurana, 2015). Social Media "is a group of internet-based applications that build on the ideological and technological foundations of web which allow the creation and exchange of user generated content... It allows users to interactively communicate with one another...and stay connected (Onah \& Nche, 2014). Additionally, "social media is an essential part of socialization among peer groups. It is used to market and motivate people to become part and parcel of a large community" (Anioke, 2017). Some of the famous social media sites are Facebook, Twitter, Instagram and YouTube, the well-known video site. These avenues or medium in social interaction and communication does not only give online connection between people especially the young people, but they also use social media as a form of "entertainment" and "convenience". Social media sites have been "immensely growing due to the fast-paced demand and consumption of smartphones, computers and other gadgets. In Facebook, a person can add up to five thousand friends or contacts and they can easily gain and "add" friends even if they didn't see the person face to face, or even worse, to the point of knowing only the person "online" and not on personal relations or friendships. Social media is also an opportunity to be always updated to the current trends and updates in the world. Famous celebrities, internationally or locally, have their Twitter and Instagram accounts wherein they can easily be "followed" and "liked" by their fans. Moreover, this 
\#LIKEORUNLIKE: A study on the effects of social media on the moral development of the young people

social media sites can help persons to express themselves freely and gain sympathy or support, which is why many people are hooked in posting status or "hugot" lines (statements to announce sentiments and feelings to public) to get support, empathy and affirmation.

For instance, in the Philippines, research tells that the country was the top among other countries with $83.1 \%$ Filipinos belonging to social networking sites and it was also the Filipinos, who became top users who frequently share photos and videos to their social media sites. Apparently, the growing number of social media users are students or whose Filipinos aged 15 to 24 years old (Duque, San Antonio, Brazil, 2017). Moreover, according to Fleire Castro, in her study last January 2016, she said that the Philippines is the "Social Media Capital of the World" with 44 million Filipinos who are Internet users and 40 million of them are active social media users... The percentage of social media penetration has increased from $40 \%$ in 2015 to $47 \%$ in 2016 (Castro, 2016).

\subsection{Social media: Benefits and disadvantages}

Social media has various effects in the lives of people particularly to young people. It has positive outcomes or effects but at the same time, it also produces negative impacts or disadvantages on the part of the netizens. Research tells that there are advantages of social media such as the following: convenient access to information, fast and efficient communication with other people, promoting tool for businesses and collaborative environment and it is a great help in the field of education (Ali Aljabry et al., 2017). In addition to that, social media can serve as easy source of information for academic purposes... It has the power that in just a click, one passes information to many people in just a second. It has made business, politics and social life uncomplicated and easy by the fact that it can be accessible with mobile smartphones anywhere and at any time" (Onah \& Nche, 2014). Social media "also contribute in the improvement of work efficiency in the office and business centers.

Moreover, research also added benefits or good points in using social media and internet. Development benefits of social media are as follows: good literacy skills, social skills, intellectual benefits like developing problem solving and critical thinking, creative benefits (by using imagination, art and modeling, music and media through the use of software), political and social awareness by watching news, current affairs and documentaries, valuing through observing role models in media, and the use for entertainment and relaxation purposes to relieve boredom and for social interaction. He also said that social media "increase reading, writing and critical thinking skills through using blogs, chat room, and help them becoming in message boards" (Anioke, 2017).

In addition, social media also helps to develop relationships. "It develops the communication through the act of socializing. These social networking sites enable users to interactively connect, share images, audios, and videos to contacts online. They offer users opportunities to meet long lost friends, make new ones, meet family members or friends who might be in other location and stay connected" (Onah \& Nche, 2014). Social media also offer them "a platform to connect with new people, share experiences and gain exposure (Khurana, 2015).

On the other hand, social media may also lead to some negative effects, specifically in the actions and attitudes of the young people. Interpersonal relationship in the family starts to diminish. The young people use social media "as a tool for posting the problems and sharing emotions that they are going through. Due to this habit, the privacy or the things that must be shared and remain within the members of the family, especially with parents has also declined. Many parents may feel comfortable that their children are properly using online applications and websites but they find it difficult to relate to the rapid development in information technology and to their technologically-inclined children due to their insufficient technical abilities. On the side of parents, social media seems to be a hindrance for them to talk to their child face-to-face. Because of this technological trend, parents nowadays do not know the interest of their children until they post it on social media. Also, they do not know on how they can find time to have a better communication and to spend more time with their children (Duque, San Antonio, Brazil, 2017). One factor could be the parents or guardians "lack a basic 
understanding of these new forms of socialization which are integral to their children's lives. They do not have technical abilities to keep pace with their children in the social media and internet world" (Anioke, 2017). Sadly, Children tend to spend more time in using Facebook or Twitter rather than talking to their parents and tell stories on their personal lives and how do they do in school, relationships etc. They tend to keep themselves busy in their "new social environment" and not already willing to converse personally, rather they will just make a "PM" or "personal message" in Messenger on you even if the person they are talking to is with them at home. "For one thing, modern teens are leaning to do most of their communication while looking at the screen, not on the other person... Social media creates a non-verbal social skills in a way of texting and online communication... putting everybody in a nonverbal disabled context, where body language, facial expression, and even the smallest kind of vocal reactions are rendered invisible" (Ehmke, 2017).

Internet and social media "make people staying in touch easier when family members are physically apart, but it can also keep them apart when they are at home (Onah \& Nche, 2014). It seems that the youth nowadays has "double lives or faces", namely the "offline life or face" or the usual face to face encounter with people, and the "online life or face" where in they engage themselves more actively in the virtual or digital world. With this, the Catholic Church through the Synod of Bishops on Young People, the Faith and Vocational Discernment declares that "Digital media can expose people to the risk of dependency, isolation and gradual loss of contact with concrete reality, blocking the development of authentic interpersonal relationships"(Synod of Bishops, 2018). Thus, these social networking sites "do not provide an opportunity to build stronger contacts with people than in person (Khurana, 2015).

Another disadvantage of using social media is that there is a tendency that it leads young people to "moral decadence or degeneration". A study shows that there is "a consistent and unopposed abandonment and overlook of moral principles of conduct in a society by members of the society". For example, these social media sites "have also served as way for some young people to share rude, nude and sexual images, especially of themselves". Another instance is that too much usage of social media without proper guidance will lead to indecent dressing and sexual harassment. Hence, this medium is also "used by cyber-criminals also known as Internet hackers and scammers wherein they break codes and passwords to gain an unauthorized access to computer system in order to make money". Sadly, another thing that social media can influence to the young people is when facing disasters in which people were injured and killed, they rather take pictures or recording the catastrophe and the victim with their smartphones and then upload it online, instead of getting help for the victim (Onah \& Nche, 2014). Moreover, in Africa, "more than eighty percent of their children are spending a large amount of time surfing the Internet. It was introduced to them at a very young age into their lives... It affected the African child's academic life. They just download, copy and paste" (Anioke, 2017). With this, there is a great hazard when it comes on what the young people get online. They need moral guidance. Parents should always be there to guide and assist them to tell apart what is good and bad, for not everything in the online realm is right. It is like comparing social media into a marketplace or pharmacy wherein they need to accompany their children in choosing what good for them.

One more disadvantage of using internet and social media to the young is the development of "Impatience and Quick Syndrome". With its promptness, automation, and highly vast speed in carrying out activities has already influenced patience and endurance to people. This is evident in the rushed and impatient lifestyle found among young people who wanted to get everything so quick through the Internet and Social Media (Onah \& Nche, 2014). Even our communication is becoming so brittle and blunt. The verbs found in our speeches show inner compulsion of speed. We 'snatch' a file; 'dash off' to a meeting; or 'catch' a plane or flight. The loss of patience among the young people seems to be furnishing the 'get-rich-quick syndrome" (Mefoh, 2007). In addition to this, in the event of having social gatherings, it is "hampered due to surfing in social networking sites which keep them more involved for which they are bound to ignore other significant social events in their lives" (Khurana, 2015).

Sadly, another weakness or disadvantage of using social media in the lives of young people is the possibility 
of being exposed the different physical and mental threats such as "online harassment or cyber-bullying (the process of using digital media to make and communicate false and embarrassing information about another person), sexting and pornography (sending or forwarding recorded sexually explicit videos, messages, images, through mobile phones, computer or other gadgets or digital devices) and depression which may lead to substance abuse, suicide, unsafe sexual practices and oppressive destructive behavior” (Anioke, 2017).

\subsection{The young people and social media: Looking into Kohlberg and Fowler's theories of moral development}

\section{and faith maturity}

In the advent and fast outbreak of social media and internet, the concern now is in its moral implication or impact in the lives of the young people. With this, connecting media and morality must be not be taken for granted. "Children learn by observation and imitation... They imitate what they see and what others do around them. They are not yet matured enough to separate good from bad. Hence, the need for close observation to assist them to grow to maturity" (Anioke, 2017). Therefore, social media and internet can also give possible negative moral effects on children. It can greatly influence the young people on how to judge right and wrong.

First, Lawrence Kohlberg, an American Psychologist, discovered and studied the "Six stages of Moral Development". There are three levels. The first level is called the "pre-conventional" level. At this point, children respond to rules and labels of good and bad, right or wrong based on the physical consequences of their actions. They will show obedience to authority to avoid being punished. Actions or responses are done to obtain rewards. The second level is the "conventional" level. In this stage, young adults or adolescents begin to set moral actions to meet expectations from others. In other words, views of other people matter or count in the moral decision of the person. Seeking approval, avoidance of blame, pleasing others, and the feeling of belonging or to get involved is visible in this level. Moreover, in this level, the importance of doing one's duty on certain rules, laws and social codes is being given stress.

Lastly, the third level of Kohlberg's theory on Moral Development is called the "post-conventional" level. It is also known as the "autonomous or principled stage". In this level, moral principles and values were defined clearly. An individual can now differentiate moral and legal right. At the same time, the mentality of breaking the rules sometimes if enough groups agree to it is being expressed. The person looks for justice and equality of dignity of all people. Hence, looking in the theory of Lawrence Kohlberg, it is important that the young people must be guided in their moral decision making, most especially in their engagement in social media and Internet. The levels of Moral Development will tell that children need guidance for them to choose, prize and act upon what is right. This will give way to the vital role of parents and authorities in their mission for their children's moral values formation. In the first level, parents must be "morally grounded" and hands on in these primary years of the child in their life. Children will respond to them based on what they teach or command, and that's what they think is right. While on the second level, children observe certain rules given by their parents to set as moral standard. Finally, on the third stage, the young adults can now distinguish right and wrong and does not believe right away to what is being said to them because their moral values is grounded well by their parents before until the present. Obviously, moral behavior can be learned through imitation and role modeling. And the parents are the first teachers of the children. In this contemporary world, Internet and social media is the new "social environment" of our young people and not everything in the web is right and good for them.

Another emerging theory that can be anchored in this study is the "Faith Development" theory of James Fowler, an American Theologian and Professor who became famous in his "six stages of faith development". And faith is very essential element when it comes to moral development. Faith can affect one's values and principles in life. James Fowler thinks his faith development theory is well-matched with established theories of identity development such as Erik Erikson's psychosocial development and Jean Piaget's Cognitive Development Theory. "Fowler's theory of faith development presents a six-stage hierarchical scheme. He concluded that the stages of faith development range from stage one, early childhood period-dependency to stage six, adulthood-universalizing faith. Each stage distinctively identifies the process of growth that individuals 
Quimson, L. O., Jr.

experience. Each growth stage is dependent upon a person's relationships with others and his or her level of cognitive development and moral reasoning" (Haggray, 1993).

This study will just focus on the first three stages of Fowler's Faith Development because it only focuses on the young people until adolescence stage. The first stage is the "Intuitive-Projective Faith" from age two to six years old. It "begins with convergence of thought and language...the use of symbols in speech and ritual play. This is the fantasy-filled, imitative phase in which children can be powerfully influenced by examples, moods, actions, and stories of the visible faith of adults" (Haggray, 1993). While the second stage of his theory is about the "Mythic-Literal Faith" from age ten years old. During this age, a child "begins to take on for him or herself the stories, beliefs, and observances that symbolize belonging to his or her community... Coherence and meaning become linear and stories become the major way of giving unity and value to one's own experiences. Fowler contends this is the faith stage of the school child... The danger in this stage is the child's limitation of literalness and excessive reliance upon the principle of reciprocity, a sense of controlling and embracing negative actions toward mistreatment may become apparent" (Haggray, 1993).

And last on the first three stages of Faith Development is Synthetic-Conventional Faith (Adolescence) The adolescent, on this level or stage, "begins to externalize authority. The adolescent's experience of the world extends beyond family to peers, school, society, work, play, and religion... In this stage the adolescent is apt to develop conformity... The adolescent in this stage will normally develop suspicions of those with whom he or she do not have trusting relationships" (Haggray, 1993). Therefore, following and considering the theories of both Kohlberg and Fowler, it is really evident that the young age of the child until adolescence is really vital and parental guidance and supervision is necessary for the moral formation and development of the children. If the parents, guardians and even teachers will monitor and check the young people as they explore their "new social environment" or social media, then these children will be guided on right or good valuing, on choosing what is morally acceptable and they will carry it out until adulthood.

\section{Methodology}

The researcher conducted the study through descriptive method and qualitative approach. Five students from the University of Santo Tomas Senior High School were interviewed by the researcher with the use of guide questions and voice recorder for future documentation of data and experiences. The respondents were selected by the researcher based on their frequency in usage of social media to make the research valid. The following are the questions asked to the respondents regarding the study:

$>$ Do you often use social media? Do you think how many hours a day do you use?

$>\quad$ What social media apps do you use?

$>\quad$ Why do you use social media?

$>\quad$ Does the usage of social media help you? If yes, what are they?

$>$ Does the usage of social media also have negative effects? What are those?

\section{Results and discussion}

The result of the interview says that all the respondents frequently use social media sites and Internet. The average number of hours that the five respondents gave in using social media is 9.6 hours a day. The four major social media sites that they use are the following: Facebook, Instagram, Twitter and YouTube. When they were asked why they use social media, here are the top reasons. First, social media is their source of entertainment and relaxation. Through social media, they are relieved from stress by the "memes", jokes and "tweets" that they see, the videos and movies that they watch online, through the music that they listen to and lastly, they were entertained by social media that's why it is a good hobby or pastime in order not to be bored. Second, they use

50 Consortia Academia Publishing (A partner of Network of Professional Researchers and Educators) 
social media to easily communicate with people, to their families especially those who are far from them and even to their friends. And third, they use social media sites to keep updated on the latest news, information and other things such as sports and music. They also use these apps as watch tutorial videos in the net and learn many things all by themselves.

When they were asked if social media had helped them, all said yes. Majority of them said that social media is a very good avenue, form or medium to fast communicate information, to freely express themselves and to easily receive latest news and updates instead on relying to television and text messages. In using social media, they can also gain confidence or self-esteem and affirmation through the "likes", "comments" and validations in their posts that they receive from others. The fact that social media is always available, and it is on their fingertips, they do not experience boredom because everything that social media shows is their interest. Instead of calling or asking other people, they will prefer to open their smartphones and browse in the social media because there is a tendency to be rejected and opposed and at the same time, they don't want to disturb others about telling their concerns. Again, social media is a way for them to relax and be entertained to be relieved from stress. Finally, social media is also a great help on their studies and researches.

On the other hand, the respondents also revealed that there are also negative effects or disadvantages in using social media. Majority of them said that the reality of "cyberbullying", spreading "fake news", hatred and anger in social media gives an idea that the web is not at all healthy in the eyes of young people. Sharing ill-feelings, envy and being compared to others and compete with what they have is the dictum of social media. If not solved right away, it may lead to depression and the worst is death due to pressure and negative comments of others. Secondly, social media is also an addiction that can be a disturbance in doing important things such as studies and other priorities in daily life. It can delay work because it may "sidetrack" the momentum of a person when accomplishing something. Thirdly, social media makes someone "rely on it in order to make an image that he/she is loved and accepted." They make a new self, but it is not their "real self" because if they will not do that, they are not "in" and accepted. In social media, they wanted to please others to receive good feedbacks. In short, it promotes false identity and full reliance to social media to live. Another negative impact on the use of social media is that it becomes dangerous for young people because everything can easily be accessed and they will be tempted not to ask help anymore from other persons or "experts" for information is already offered to them on their fingertips. There is a tendency that they will just absorb everything that they have seen and treat it all as correct. Sadly, this reality can lead to "the instant mentality" where in they will just do it all by themselves to accomplish it without consulting or asking the feedback and suggestion of others. Lastly, social media can also make life luxurious and develop an attitude of "no contentment" in life. In the advent of online shopping sites, people will easily be tempted to consume and buy many cheap materials even if they don't need it at that time in order to secure and establish oneself and make a name to other people. It does not anymore promote simplicity and happiness in satisfaction in life.

At the end, the student respondents shared that there are also effects of social media with regards to their character formation and moral values. They said that using social media promotes "two-sided morality" or distortion of values. For example, a person seeing bullying online feels that it is just right, but when he or she or maybe some of his or her relatives and friends is in the situation, it is another story. Thus, it promotes indifference. Another instance is that "if an action is already done by many, why is it that it is still questioned?" If many does it, it means it is right. This is another misrepresentation of morals. Secondly, using social media makes young people not anymore interact "face to face". There is a tendency that in social media, you will just be entertained and not be judged. They will create their "own world" without minding anymore the persons around you in the "real world". Meanwhile, someone said that social media also "dictates what they should be". It creates a standard that they must follow or else they will be out and not accepted by others. Sadly, it also makes young people to have "ill-feelings or attitude" to others such as greed and envy. They already adapting the "westernized" values, instead of becoming accustomed to Filipino values. But on the positive note, there are also respondents who said that social media makes them aware to be "in moderation" or to have control in its usage. It also teaches them that while having these social media sites, their personal lives must be separated from it. 
Quimson, L. O., Jr.

Young people must know how to distinct "virtual world" from "real world".

\section{Conclusion}

This study therefore concludes that social media has a great impact in the lives of the students, specifically in moral development. It is already a reality in this world that no one can stop, and people must learn how to use it well. Moreover, social media offers a lot of benefits such as being a tool for entertainment and relaxation, a very useful tool for easy communication and access to latest news and updates, and it could also enhance their manner of reviewing lessons in their studies. However, social media doesn't have only lights but also shadows. It also has negative impact to the lives of the young people such as spreading threats like "cyber-bullying", fake news, hatred, and anger. Aside from that, it can distort moral values or mindset and make surfing in the net an addiction which may lead them to be individualistic or make their own world and not anymore prioritize the "real world" with their family and persons around them. Our Holy Father Pope Francis in his apostolic exhortation "Amoris Laetitia" said that there is a "growing danger represented by an extreme individualism which weakens family bonds and ends up considering each member of the family as an isolated unit, leading in some cases to the idea that one's personality is shaped by his or her desires, which are considered absolute. The tensions created by an overly individualistic culture, caught up with possessions and pleasures, leads to intolerance and hostility in families" (Francis, 2016). Lastly, it can make the mentality of luxurious and materialistic.

But this sad outcome can still be solved, and the solution lies on the people who can guide the young people on using social media. And we are referring to the parents, guardians, religious educators, or catechists and even Church leaders. Here are some recommendations for the following important sectors in the moral development of the young people:

For the parents and guardians, it is really a must to guide, monitor and educate their children as they grow up and explore the right usage of social media and internet. St. John Paul II in his apostolic exhortation Familiaris Consortio tells that "since parents have conferred life on their children, they have a most solemn obligation to guide their offspring". (John Paul II, 1981) This role from the parents is really essential for the young people because just like what Kohlberg and Fowler tell in their studies and theories that values are really formed in the primary years of the children. What they've been through and learned when they were young would really be carried out as they grow, and it becomes their moral principle. Children develop their morals and faith in the family, the "domestic Church" through their parents' upbringing. Parents must always be there on their side to address their needs and not anymore treat social media as their "virtual parents". They need love, care, and personal attention. Likewise, There must be an avenue for the young to manifest love through good works and charity (del Castillo, 2013). Without doing this, the young people will be at risk and may absorb everything that social media offers to them. The Church also teaches that "parental supervision should include making sure that filtering technology is used in computers available to children when that is financially and technically feasible, in order to protect them as much as possible from pornography, sexual predators, and other threats. Unsupervised exposure to the Internet should not be allowed. Parents and children should dialogue together about what is seen and experienced in cyberspace; sharing with other families who have the same values and concerns will also be helpful. The fundamental parental duty here is to help children become discriminating, responsible Internet users and not addicts of the Internet, neglecting contact with their peers and with nature itself" (Pontifical Council for Social Communication, 2002).

Lastly, for the Church leaders and catechists, they must continue to pursue in teaching and living the faith which is also an avenue in forming moral values to the young people. St. Paul VI proclaimed that "the first means of evangelization is the witness of an authentically Christian life, given over to God in a communion that nothing should destroy and at the same time given to one's neighbor with limitless zeal... Modern man listens more willingly to witnesses than to teachers, and if he does listen to teachers, it is because they are witnesses" (Paul VI, 1975). They must learn to live the faith and share the faith in social media. "Young people in particular

52 Consortia Academia Publishing (A partner of Network of Professional Researchers and Educators) 
\#LIKEORUNLIKE: A study on the effects of social media on the moral development of the young people

need to be taught "not only to be good Christians when they are recipients but also to be active in using all the aids to communication that lie within the media...So, young people will be true citizens of that age of social communications which has already begun...Teaching about the Internet and the new technology thus involves much more than teaching techniques; young people need to learn how to function well in the world of cyberspace, make discerning judgments according to sound moral criteria about what they find there, and use the new technology for their integral development and the benefit of others" (Pontifical Council for Social Communication, 2002).

\section{References}

Alejandrino, M. P. R., Catipay, J. D., Concepcion, P. V. A. T., Flores, S. M. C., Palicte, C. M. D., \& Seguiro, A. C. (2018). Social media addiction and study habits of senior high students. International Journal of Engineering Technology Research \& Management, 2(6), 8-12. http://doi.org/10.5281/zenodo.1257000

Ali Aljabry, A. M., Ahmed Jaafari, A. A., Mohammed Salawi, M. A., Taher Majrabi, F. A., Ahmed Hazzazi, N. M., A Khormi, A. H., Mousa Daghriri, A. A., Abdullah Alfaqih, A. M., Mohmmed Al-harobi, M. A., \& Musa Alqahtani, S. A. (2017). Effect of social media network on social relations and academic achievement among medical students. Egyptian Journal of Hospital Medicine, 69(7), 2910-2917. https://doi.org/10.12816/0042585

Anioke, J. N. (2017). Media effects on children's social and moral development: A theological moral study in Africa. Journal of Cultural and Religious Studies, 5(3), 113-132. https://doi.org/10.17265/2328-2177/2017.03.001

Castro, F. (2016). Social media and digital stats in the Philippines 2016 (We are social data). Third Team Media. http://fleirecastro.com/guides/social-media-and-digital-stats-in-the-philippines-2016wearesocial-data/

del Castillo, F. (2013). Love constructs among college students: A religious exploration. Lumina International Journal, 24(1), 13-22.

Duque, G., San Antonio, D., \& Brazil, L. (2017). A correlational study on social media involvement and parental relationship among students of Asia Pacific College. https://xsite.dlsu.edu.ph/conferences/dlsu-research-congress-proceedings/2017/WCF/WCFE-II-001.pdf

Ehmke, R. (2017). Social media effects on teens: Impact of social media on self-esteem. https://childmind.org/article/how-using-social-media-affects-teenagers/

Francis, P. (2016). Amoris Laetitia: On love in the family. Our Sunday Visitor. http://0search.ebscohost.com.lib1000.dlsu.edu.ph/login.aspx?direct=true\&db=edsebk\&AN=1571667\&s iteeds-live

Haggray, D. A. (1993). A description of the faith development of five students attending a church-related college. Retrospective Theses and Dissertations. https://lib.dr.iastate.edu/rtd/10438

John Paul II. (1981). Familiaris Consortio: On the role of Christian family in the modern world. http://w2.vatican.va/content/john-paul-ii/en/apost_exhortations/documents/hf_jpii_exh_19811122_fami liaris-consortio.html

Khurana, N. (2015). The impact of social networking sites on the youth. Journal of Mass Communication \& Journalism, 5(12). https://doi.org/10.4172/2165-7912.1000285

Mefoh, P. C. (2007). Technostress: The sign of the time. Deep spring.

Njoroge, R. (2013). Impacts of social media among the youth on behavior change: A case study of university students in selected universities in Nairobi, Kenya [Masteral Thesis]. University of Nairobi, Kenya.

Onah, N. G., \& Chrıstıan, N. G. (2014). The moral implication of social media phenomenon in Nigeria. Mediterranean Journal of Social Sciences, 5(20). https://doi.org/10.5901/mjss.2014.v5n20p2231

Paul VI. (1975). Evangelii Nuntiandi: Apostolic exhortation on the church in the modern world. http://w2.vatican.va/content/paul-vi/en/apost_exhortations/documents/hf_p-vi_exh_19751208_evangeli i-nuntiandi.html

Pontifical Council for Social Communication. (2002). The church and the internet. http://www.vatican.va/roman_curia/pontifical_councils/pccs/documents/rc_pc_pccs_doc_20020228_ch 
Quimson, L. O., Jr.

urch-internet_en.html

Synod of Bishops on the Young People, the Faith and Vocational Discernment. (2018). Final document. http://www.synod2018.va/content/synod2018/en/fede-discernimento-vocazione/final-document-of-the-s ynod-of-bishops-on-young-people--faith-an.html 